\title{
The effects of illness on quality of life: findings from a survey of households in Great Britain
}

\author{
Ann Bowling
}

\begin{abstract}
Study objective - To obtain national population norms on pertinent domains of quality of life, and the relative importance of these domains to people with reported longstanding illness.

Design and setting - The vehicle for the study was the Office of Population Censuses and Surveys omnibus survey in Great Britain. The sampling frame was the British postcode address file of "small users", stratified by region and socioeconomic factors. This file includes all private household addresses. The postal sectors are selected with probability proportional to size. Within each sector 30 addresses are selected randomly with an target size of 2000 adults.
\end{abstract}

Participants - The total number of adults interviewed was 2033 (one per sampled household), resulting in 2031 usable questionnaires, and representing a response rate of $77 \%$.

Main results - Of those who reported a longstanding illness, the most common, freely mentioned, first most important effects of the longstanding illness on their lives were (in order of frequency) ability to get out and about/stand/walk/go out shopping, being able to work/find a job, and effects on social life/leisure activities. Analysis of the areas of life affected by longstanding illness, showed considerable variation in relation to the condition. For example, respondents with mental health disorders (mainly depression) were most likely to report as the first most important effect the availability of work/ability to work, followed by social life/leisure activities; respondents with digestive and endocrine (for example, diabetes) disorders were most likely to report dietary restrictions; while respondents with cardiovascular disease, respiratory, and musculoskeletal disorders were most likely to report ability to get out and about/stand/ walkJgo out shopping.

Conclusions - These results support the current trend of developing disease specific health related quality of life questionnaires rather than using generic scales.

\section{(f Epidemiol Community Health 1996;50:149-155)}

There is increasing agreement among many clinicians and social scientists that quality of life should be assessed when evaluating the outcome of medical interventions. It is com- mon for investigators to use traditional health status measurement scales to measure health related quality of life, on the basis of the usually unquestioned assumption that the concepts are interchangeable. The construct validity of scales is called into question by this interchange. None of the health status scales have been rigorously assessed for their content validity as measures of health related quality of life, and none are based on the public's (healthy or unhealthy) definitions of the important areas of measurement in relation to health related quality of life. Most scales were developed on the basis of reviews of existing scales, or surveys of the public's perceptions of the effects of illness on behaviour or functioning. ${ }^{1-4}$ The public, and specific groups of patients, are the best judges of how medical conditions adversely affect their quality of lives. However, the relevant dimensions of health quality of life which should be included in measurement scales is still the subject of vigorous debate and disagreement, partly because few scales have been developed and rigorously tested using sufficiently large samples of people.

Attention is now being paid to disease specific measures of quality of life which attempt to tap domains that are relevant to people with specific conditions. Generic scales can be criticised for containing items that may be irrelevant to people with the condition under study, and for omitting others that are pertinent. Few disease specific or generic instruments have been based on a model of quality of life, few scale developers have attempted to define this concept, and few have been adequately patient based in their development, with most being based on health professionals' and scale developers' perceptions of the relevant domains for inclusion. ${ }^{5}$ However, the only valid perspective for judging the items of relevance in scale development is that of the person affected by the condition.

Several meanings have been imputed to the term "quality of life", ranging from individual fulfilment to the ability to lead a "normal" life to the satisfaction of human needs (physical, psychological, and social) (see reference ${ }^{5}$ for review). Quality of life is also dependent upon the individual's subjective perception of his achievement, which most measurement scales fail to encompass in their efforts to limit themselves to domains such as functioning (for example, domestic, return to work), the degree and quality of social and community interaction, psychological wellbeing, somatic sensation (for example, pain), symptoms, adjustment, coping, and life satisfaction. ${ }^{67}$ Philosophers, social scientists, and social 
gerontologists have a long history of concentrating on happiness, life satisfaction, independence, and control, and on the identification of the "good life" (see reference for review). This has led to the widespread definition of quality of life in social science as the extent to which pleasure and satisfaction have been obtained. ${ }^{89}$ While mental health professionals have developed their concepts of quality of life from this body of knowledge, particularly from the research on social indicators, ${ }^{1011}$ rarely have investigators concerned with the measurement of quality of life in relation to physical conditions done so.

Despite these gaps, subjective indicators based on self ratings of mental, psychological, and physical wellbeing are increasingly popular among investigators due to the recognition of the importance of how individuals feel, rather than what statistics imply they ought to feel. Promising research on health related quality of life has involved the application of the techniques of human judgement analysis to assess health related quality of life, which is a novel method of measuring this concept from the perspective of the individual. ${ }^{12-15}$ With this technique respondents are asked to list the five areas of life ("cues") that they judge to be the most important to their overall quality of life (the technique is known as the schedule for the evaluation of quality of life - SEIQoL). Open ended questions are used to elicit the relevant cues, then techniques are used of deriving relative weights of importance of each area. Simpler but similarly hermaneutic approaches to measuring disease specific quality of life were adopted by Guyatt $e t$ al in their development of quality of life scales for people with bowe disorders, respiratory disease, and heart disease. With their scales, respondents are asked to list activities that are affected by their condition, and then to specify which are the most important in their day to day lives. ${ }^{16-18}$

The research presented here aimed to begin to build up a theoretically useful body of knowledge, based on population norms, for use in health services research on health related quality of life (that is, in the evaluation of health outcomes of treatments).

\section{Aims and methods}

The aims of the research were to provide population norms on the dimensions of life that people perceive to be important in relation to quality of life and on how different conditions have different impacts on people's lives.

The hypothesis was that people with different types of conditions will report different areas of life as being affected by these. While this hypothesis seems to be "common sense", it does have implications for the debate about the design (that is, content) and use of generic and disease specific quality of life measurement scales.

The study design was an interview survey which was based on a target random sample of 2000 people in Great Britain taken by the Office of Population Censuses and Surveys (OPCS) for their monthly ominibus survey at the end of 1994. The sampling frame for the OPCS omnibus survey was the postcode address file of "small users", which includes all private household addresses, stratified by region, the proportion of households renting from local authorities, and the proportion in which the head of household is in socioeconomic groups $1-5$ or 13 (that is, professional, employer, or manager). The postal sectors are selected with probability proportionate to size, and within each sector 30 addresses are selected randomly. If an address contains more than one household, the interviewer uses a standard OPCS procedure to select just one household randomly. Within households with more than one adult member, just one person aged 16 or over is selected for interview with the use of random number tables. Because only one household member is interviewed, people in households containing few adults have a better chance of selection than those in households with many. A weighting factor is applied to correct for this unequal probability.

\section{RESPONSE}

The response rate to the survey was $77 \%$. Fourteen per cent refused to take part, $1 \%$ were incapable of interview, and $8 \%$ were not contactable. The total number of adults interviewed was 2033, and this resulted in 2031 usable questionnaires. ${ }^{19}$ The effects of the weighting procedure and the method of sampling are discussed elsewhere. ${ }^{20}$ In the analyses, percentages are rounded to the nearest whole number, from 0.5 upwards and from that downwards. Attention is drawn to differences that are statistically significant using $\chi^{2}$ tests, at least at the 0.05 level of confidence.

\section{QUESTIONNAIRE DESIGN}

Given the lack of agreement about the components and definition of quality of life, the approach taken in this research was hermeneutic and the aim was to ask respondents themselves simply about what was important in their lives (positive and negative domains). This approach to measuring quality of life was based on the questions developed for SEIQoL ${ }^{15}$ and disease specific quality of life questionnaires of Guyatt et $a l^{16-18}$ which ask people about what is important in their lives.

Respondents were first asked an open ended question about what were the most important things in their current lives (both good and bad). Respondents could mention as many items as they wished but only up to five were coded. Respondents selected the code from a showcard to represent the items mentioned, and both their free responses (which were compared with their coded responses by the researcher, to check consistency) and selected codes were recorded. The items on the showcard were chosen after analysis of the items mentioned by the respondents to the surveys of O'Boyle et $a l^{1213}$ and responses to other surveys of quality of life. Items which did not fit the pre-codes were listed and coded by the interviewers under "other"; these were analysed by the researcher and an extension to the coding 
frame was designed to enable the "other" codes to be re-coded later by OPCS coders. Respondents were then asked to place the items mentioned in rank order of importance. Both respondents' selected codes of life areas and their free responses (which were later coded back in the office) were analysed and compared. Then subjects were asked to rate their current status for each item mentioned against a categorical scale, labelled at each extremity "as good as could possibly be" and "as bad as could possibly be". Respondents were then asked to rate their overall life on a similarly labelled categorical scale.

The self rated health status and reported longstanding illness questions were based on those used in OPCS surveys. ${ }^{21-24}$ Respondents were asked the standard OPCS question: “Do you have any longstanding illness, disability or infirmity? By longstanding I mean anything that has troubled you over a period of time or that is likely to affect you over a period of time?" Respondents who said "yes" were asked what the condition was (and later about the condition that had most affected their life as a whole, over the last 12 months, if more than one was reported), and whether it "limits your activities in any way?"

Respondents who reported any limiting longstanding illness, disability, or infirmity were next also asked to define and rate the most important effects of this on their lives using the same techniques. Those who reported more than one were asked to select the condition which had most affected their life as a whole over the last 12 months for the next questions on how their lives had been affected ("thinking about your (condition ....), what would you say are the most important things in your life which have been affected by this?"). Respondents' free responses were recorded by the interviewer (and these were coded later in the office); respondents were then also asked to select codes themselves from a showcard to represent the things they had mentioned, and then list them in priority order of importance. Respondents' own coding of their free response choices and the office coding of their recorded responses were analysed and compared. The method was an adapted (simple) version of the method employed by O'Boyle et $a l^{15}$ in relation to SEIQoL. SEIQoL itself produces continuous rather than categorical data and involves the drawing of bar charts during the interview to represent the respondent's priorities. This method was too complex to be used in a large national survey (the OPCS omnibus survey uses 100 interviewers who are briefed by post, necessitating the use of conventional, standardised questionnaire design).

Data were analysed in relation to age, sex, marital status, health status, longstanding illness, disability or infirmity (and type, where numbers permitted), housing tenure, socioeconomic group, economic activity, income, social class, education, age left school, qualifications, and region. These were standard OPCS questions. ${ }^{21-24}$ Attention has been drawn to differences which were statistically significant, using $\chi^{2}$ test, at least at the $p<0.05$ level.
The generic results have been reported elsewhere in relation to differences with socioeconomic characteristics and region of residence, and with further details of the method $^{25}$; this paper reports on the most important effects of various medical conditions on people's lives.

\section{Results}

CHARACTERISTICS OF RESPONDENTS

Most respondents were married or cohabiting (68\%), owned their own home (or had a mortgage) $(75 \%), 52 \%$ were female, most left school before age $17(66 \%)$, and $37 \%$ had no educational or other qualification. Most (93\%) were white (which was expected, but precluded analyses of responses by ethnic group). Fifty one per cent of respondents were in paid employment and $55 \%$ were in social classes I, II, or IInm, $47 \cdot 1 \%$ were aged $<45$ years, $31 \%$ were 45 to $<65$ years, and $22 \%$ were $>65$ years. The full details are reported in an unpublished document about the study which is available from the author.

\section{QUALITY OF LIFE: THE MOST IMPORTANT}

THINGS IN LIFE

Respondents were most likely to mention relationships with either family or relatives as the first most important thing in their lives $(30 \%)$, followed by their own health $(25 \%)$ and the health of another person (close other/dependent other) (19\%), and finances/standard of living/housing (10\%). In relation to the second, third, and fourth most important things in their lives, respondents were most likely to select finances/standard of living/housing (selected by between 19-30\%), and social life/leisure activities was most likely to be selected as the fifth most important item (22\%). When the replies coded as "other" were analysed, this showed that the largest new categories created were "politics" and "government" and "happiness/satisfaction/well-being", although the proportions mentioning these were small $(<1-$ $3 \%)$. The final "other" category consisted largely of the importance of their pets to respondents (for example, cat, dog, horse). The full range of responses (1st to 5 th priority ranking in detail) has been reported in detail elsewhere. ${ }^{25}$ Consistency between their free responses and their selected codes was good.

The most frequently mentioned things (all priority ranks 1-5 combined), were finances/ standard of living/housing (60\%), followed by relationships with family or relatives $(54 \%)$, own health $(43 \%)$, health of other people (close) $(35 \%)$, and social life/leisure $(20 \%)$. There were some differences with age, gender, and region lived in which have also been reported elsewhere. ${ }^{25}$

HEALTH STATUS AND LONGSTANDING ILLNESS/ CONDITIONS

Fifty six per cent of respondents rated their health as "good", $29 \%$ as "fairly good", and $15 \%$ as "not good" (the latter was $3 \%$ higher 
than in the 1992 general household survey (GHS) (personal communication, Office of Population Censuses and Surveys, GHS Unit). People who assessed their health as "not good" were most likely to mention effects on the own health as the first most important thing in life generally (36\%, in comparison with $20-24 \%$ of others), and they were least likely to mention the health of (close) others ( $10 \%$ in comparison with $20-23 \%$ of others).

A relatively high proportion $(40 \%)$ reported a longstanding illness, disability, or infirmity, and $60 \%$ of these reported that it limited their activities in some way. The proportion who reported a longstanding illness was similar to the proportions reported in the 1991 and 1992 OPCS health survey ${ }^{2324}$ and, as with the latter, the proportion was $4 \%$ higher than the proportion reporting this in the GHS. ${ }^{21}{ }^{22}$ In relation to this difference, OPCS reported that people might have been more likely to report an illness in the health survey because they were taking part in a health survey rather than a general survey. ${ }^{24}$ In the case of the present study, although health was not mentioned until health status and longstanding illness were asked about later in the questionnaire (that is, after the generic questions about the important things in life), it is possible that respondents were more sensitised to health as they knew that the set of questions was asked on behalf of "St Bartholomew's Hospital Medical College", where the author was then based.

The interviewer coded the number of longstanding illnesses/disabilities/infirmities (LSI) reported; $27 \%$ of all respondents reported just one and $13 \%$ reported multiple conditions. The conditions mentioned were coded in the office by OPCS, using the coding frame developed for the OPCS health survey. The conditions most frequently mentioned by the $40 \%$ were hay fever $(15 \%)$, back problems $(11 \%)$, hypertension (6\%), and musculoskeletal problems (usually arthritis) (6\%). These conditions were also coded into more global categories: the conditions that were most frequently mentioned (by the $40 \%$ ) as affecting respondents' lives were diseases of the respiratory system $(29 \%)$, diseases of the musculoskeletal system $(17 \%)$, and diseases of the heart and circulatory system (cardiovascular) (14\%). Various other conditions were mentioned by between $<1 \%-7 \%$ of the sample.

\section{FIRST MOST IMPORTANT AREA AFFECTED BY} LONGSTANDING ILLNESS/CONDITION, AND ALI AREAS MENTIONED AS IMPORTANT

The most commonly freely mentioned first most important effects of the longstanding illness on their lives were (in order of frequency) ability to get out and about/stand/walk/go out shopping (mentioned as first most important by $25 \%$ ), being able to work/find a job (14\%), and effects on social life/leisure activities (13\%), and physical effects and symptoms $(9 \%)$. When respondents selected codes from a showcard in relation to health effects, however (prior to the office recoding), there were some discrepancies with their (office coded) verbatim replies. The showcard apparently had the effect of prompting them to code areas of life that they had not previously mentioned to the interviewer. Consequently, the most commonly mentioned first most important effects of the longstanding illness on their lives (when coded from the showcard by respondents) were (in order of frequency) pain (20\%), tiredness/lack of energy/lethargy (16\%), social life/leisure activities $(14 \%)$, and availability of work/ability to work (10\%).

When priority ranks $1-5$ are combined, the most frequently mentioned (free responses) area of life affected was ability to get out and about/stand/walk/go out shopping (36\%), followed by social life/leisure activities (28\%), availability of work/ability to work (19\%), other specific physical effects/symptoms (these included, having to carry tablets around, being out of breath, embarrassment about scars, bladder control affected by medication) (18\%), ability to do housework/clean home/carry shopping/gardening/other similar activities (13\%), depression/worry/anxiety/unhappiness (12\%), and other restrictions on activities (these included swimming, football, other sports, dancing, playing with/carrying children, driving, reading and playing with pets) $(11 \%)$. Other areas were mentioned by between 1 and $7 \%$ of respondents (full tables available from the author).

In contrast to the first most important area affected, there were some gender and age differences with the frequency with which all areas (1-5 combined) were mentioned. Males were more likely than females to mention their social life/leisure activities ( $33 \% v 24 \%$ ) and availability of work/being able to work $(24 \% v 15 \%)$. Women were more likely than men to mention depression/worry/anxiety/unhappiness $(16 \% v 7 \%)$. In relation to age, younger respondents were more likely than older respondents to mention availability of work/ability to work. Between $21 \%$ and 33\% of respondents aged $<25$ to $<55$ years mentioned this compared with $19 \%$ of people aged $55<65$ years and $3 \%-5 \%$ of respondents aged $65<75$ years and $75+$ years respectively. Mention of ability to get out and about was most frequent among older respondents: this was mentioned by between $10 \%$ and $27 \%$ of respondents aged $<25$ to $<55,44 \%$ of those aged $55<65$, and $56 \%$ to $59 \%$ of those aged 65 years and over.

Gender differences generally held when controlling for age and marital status (although they did not achieve statistical significance due to small base numbers); they were either more pronounced, or new differences emerged within specific age groups. Results were less consistent in relation to income, qualifications, social class, and housing tenure.

TYPE OF LONGSTANDING ILLNESS OR CONDITION AND EFFECTS ON LIFE (FIRST MOST IMPORTANT THING, AND ALL PRIORITIES 1-5 COMBINED) (WITH OFFICE CODING OF "OTHER") Table 1 shows type of condition and the first most important effect of the longstanding ill- 
Table $1 \mathrm{~A}$ Type of longstanding illness or condition and areas of life most affected (with office coding of "other" category): first most important area and all areas (priorities $1-5+$ ) mentioned

\begin{tabular}{|c|c|c|c|c|c|c|}
\hline \multirow[t]{2}{*}{ Area affected } & \multicolumn{2}{|c|}{ Disorders of the respiratory system } & \multicolumn{2}{|c|}{ Disorders of the digestive organs* } & \multicolumn{2}{|c|}{ Disorders of the musculoskeletal system } \\
\hline & $\begin{array}{l}\text { First most important } \\
(\%)\end{array}$ & $\begin{array}{l}\text { Mentioned at all } \\
(1-5)(\%)\end{array}$ & $\begin{array}{l}\text { First most important } \\
(\%)\end{array}$ & $\begin{array}{l}\text { Mentioned at all } \\
(1-5)(\%)\end{array}$ & $\begin{array}{l}\text { First most important } \\
(\%)\end{array}$ & $\begin{array}{l}\text { Mentioned at all } \\
(1-5)(\%)\end{array}$ \\
\hline $\begin{array}{l}\text { Relationships with family/ } \\
\text { relatives }\end{array}$ & 1 & 3 & 1 & - & 4 & 4 \\
\hline Relationships with other people & - & 4 & - & - & - & 1 \\
\hline $\begin{array}{l}\text { Health of someone close } / \\
\text { responsible for }\end{array}$ & 1 & 1 & - & - & - & - \\
\hline $\begin{array}{l}\text { Financial security/housing/ } \\
\text { standards of living }\end{array}$ & 2 & 2 & - & - & 1 & 4 \\
\hline $\begin{array}{l}\text { Conditions of work/job } \\
\text { satisfaction }\end{array}$ & - & 3 & - & - & 3 & 3 \\
\hline Availability of work/able to work & 15 & 13 & 20 & 24 & 17 & 26 \\
\hline Social life/leisure activities & 2 & 33 & 9 & 16 & 24 & 36 \\
\hline Pain & 5 & 11 & 2 & 12 & 5 & 12 \\
\hline Treatment side effects & - & - & 2 & 5 & - & - \\
\hline Tiredness/lack of energy & 4 & 5 & 1 & 2 & - & 3 \\
\hline Nausea/vomiting & - & - & - & - & - & - \\
\hline Other physical effects/symptoms & 10 & 19 & 21 & 25 & 4 & 4 \\
\hline $\begin{array}{l}\text { Depression/worry/anxiety/ } \\
\text { unhappiness }\end{array}$ & 3 & 8 & 5 & 9 & 一 & 6 \\
\hline Mental confusion & 1 & 1 & - & 2 & - & - \\
\hline Other mental health problems & - & 1 & - & 2 & - & - \\
\hline Effects on sex life & - & - & - & - & 1 & 1 \\
\hline $\begin{array}{l}\text { Ability to get out about/stand/ } \\
\text { walk/go out shopping }\end{array}$ & 35 & 52 & 5 & 9 & 24 & 36 \\
\hline $\begin{array}{l}\text { Ability to do housework/clean } \\
\text { home/carry shopping/gardening/ } \\
\text { other similar activities }\end{array}$ & 8 & 17 & 2 & 2 & 5 & 14 \\
\hline Other restrictions on activities & 4 & 8 & 2 & 9 & 11 & 17 \\
\hline Dietary restrictions & 1 & 1 & 25 & 40 & - & - \\
\hline Effects on appetite & - & - & - & - & - & - \\
\hline $\begin{array}{l}\text { Other (eg, education, } \\
\text { environment) }\end{array}$ & 3 & 4 & 4 & 6 & 1 & 2 \\
\hline No of respondents & 173 & 173 & 41 & 41 & 114 & 114 \\
\hline
\end{tabular}

* Caution, small numbers

Some cell numbers do not equal the total due to weighting and multiple response procedure for the 1-5 combination.

Table $1 B$ Type of longstanding illness or condition and areas of life most affected (with office coding of "other" category): first most important area and all areas (priorities $1-5+$ ) mentioned

\begin{tabular}{|c|c|c|c|c|c|c|c|c|c|c|}
\hline \multirow[t]{2}{*}{ Area affected } & \multicolumn{2}{|c|}{$\begin{array}{l}\text { Endocrine } \mathbb{E} \\
\text { metabolic disorders* }\end{array}$} & \multicolumn{2}{|c|}{$\begin{array}{l}\text { Mental health } \\
\text { disorders* }\end{array}$} & \multicolumn{2}{|c|}{$\begin{array}{l}\text { Disorders of the } \\
\text { nervous system* }\end{array}$} & \multicolumn{2}{|c|}{ Eye complaints* } & \multicolumn{2}{|c|}{$\begin{array}{l}\text { Disorders of the heart } \mathcal{E} \\
\text { circulatory system }\end{array}$} \\
\hline & $\begin{array}{l}\text { First most } \\
\text { important } \\
(\%)\end{array}$ & $\begin{array}{l}\text { Mentioned } \\
\text { at all } \\
(1-5)(\%)\end{array}$ & $\begin{array}{l}\text { First most } \\
\text { important } \\
(\%)\end{array}$ & $\begin{array}{l}\text { Mentioned } \\
\text { at all } \\
(1-5)(\%)\end{array}$ & $\begin{array}{l}\text { First most } \\
\text { important } \\
(\%)\end{array}$ & $\begin{array}{l}\text { Mentioned } \\
\text { at all } \\
(1-5)(\%)\end{array}$ & $\begin{array}{l}\text { First most } \\
\text { important } \\
(\%)\end{array}$ & $\begin{array}{l}\text { Mentioned } \\
\text { at all } \\
(1-5)(\%)\end{array}$ & $\begin{array}{l}\text { First most } \\
\text { important } \\
(\%)\end{array}$ & $\begin{array}{l}\text { Mentioned } \\
\text { at all }(1-5) \\
(\%)\end{array}$ \\
\hline Relationships with family/relatives & 6 & 6 & 14 & 19 & - & 4 & - & 4 & 1 & - \\
\hline Relationships with other people & - & - & 9 & 20 & 3 & 3 & 1 & 3 & - & 1 \\
\hline Health of someone close/responsible for & - & - & - & - & - & - & - & - & 1 & 1 \\
\hline $\begin{array}{l}\text { Financial security/housing/standards of } \\
\text { living }\end{array}$ & 2 & 12 & 7 & 19 & - & - & - & - & 2 & 7 \\
\hline Conditions at work/job satisfaction & - & - & 3 & 7 & 1 & 1 & - & - & - & - \\
\hline Availability of work/able to work & - & - & 21 & 36 & 27 & 42 & 12 & 15 & 15 & 17 \\
\hline Social life/leisure activities & - & 12 & 19 & 31 & 6 & 24 & 7 & 20 & 2 & 26 \\
\hline Pain & - & 5 & - & - & - & 3 & 9 & 12 & 5 & 7 \\
\hline Treatment side effects & 2 & 17 & - & - & - & - & - & 3 & - & 1 \\
\hline Tiredness/lack of energy & 11 & 18 & - & 7 & - & 7 & 5 & 7 & 2 & 6 \\
\hline Nausea/vomiting & - & - & - & - & 3 & 3 & - & - & - & - \\
\hline Other physical effects/symptoms & 15 & 18 & - & 2 & 13 & 21 & 8 & 26 & 12 & 24 \\
\hline Depression/worry/anxiety/unhappiness & 8 & 17 & 17 & 27 & 17 & 14 & 3 & 9 & 6 & 18 \\
\hline Mental confusion & 3 & 3 & - & 2 & - & 3 & - & - & - & - \\
\hline Other mental health problems & - & _ & - & - & 3 & 7 & - & - & 3 & 5 \\
\hline Effects on sex life & - & - & - & 5 & - & - & - & - & - & - \\
\hline $\begin{array}{l}\text { Ability to get out about/stand/walk/go out } \\
\text { shopping }\end{array}$ & 9 & 15 & 5 & 15 & 20 & 21 & 30 & 45 & 33 & 42 \\
\hline $\begin{array}{l}\text { Ability to do housework/clean home/carry } \\
\text { shopping/gardening/other similar activities }\end{array}$ & 2 & 2 & 2 & 5 & 1 & 13 & 7 & 28 & 7 & 18 \\
\hline Other restrictions on activities & - & 6 & - & - & 10 & 13 & 18 & 26 & 9 & 15 \\
\hline Dietary restrictions & 38 & 48 & - & - & - & 3 & - & 4 & 1 & 3 \\
\hline Effects on appetite & - & - & - & 5 & - & - & - & 3 & - & 1 \\
\hline Other (eg, education, environment) & 5 & 6 & 3 & 3 & 7 & 7 & - & 3 & - & - \\
\hline No of respondents & 33 & 33 & 30 & 30 & 36 & 36 & 38 & 38 & 75 & 75 \\
\hline
\end{tabular}

* Caution small numbers

Some cell numbers do not equal the total due to weighting and multiple response procedure for the $1-5$ combination.

ness/condition on respondents' lives, and all areas combined into an overall frequency with which the area was mentioned. The conditions which were excluded for presentation in Table 1 include neoplasms, ear complaints, genitourinary conditions, skin conditions, infections, and disorders of the blood where base numbers were 15 or less.

The most important areas of life mentioned in relation to the effects of specific conditions were different to those mentioned generically. Table 1 shows consistency, on the whole, be- tween the first most important area of life affected by the condition, and the most frequently mentioned area (1-5 priority ranks combined). For example, it shows that people with mental health problems and disorders of the nervous system were all most likely to rate availability of work/able to work as the first most important area affected and the most frequently mentioned area. People with eye conditions, cardiovascular disease, respiratory disease, and disorders of the musculoskeletal system were all most likely to mention ability to get out and 
about as the first most important area and it was the most frequently mentioned area (1-5 combined). Respondents with digestive and endocrine disorders were most likely to mention dietary restrictions as the first most important effect, and as the most frequently mentioned effect (1-5).

In some cases the different distributions of frequencies with which areas were mentioned as either first most important or mentioned at all (1-5) leads to differences in terms of magnitude. For example, in relation to respiratory disease and ability to get out and about (35\% first most important: $52 \%$ mentioned at all (1-5)), and cardiovascular disease and ability to get out and about (33\%:42\%), and in relation to musculoskeletal conditions and effects on social life ( $24 \%: 36 \%$, respectively) and respiratory conditions and effects on social life $(2 \%: 33 \%)$. The base numbers of people with genito-urinary conditions $(n=15)$, ear complaints $(n=13)$, neoplasms $(n=11)$, skin conditions $(n=5)$, diseases of the blood and related organs $(n=3)$, and infectious and parasitic conditions $(n=2)$ are too small for interpretation.

\section{Summary and discussion}

The research presented here highlights the need for more sensitive measurement of health related quality of life. Respondents were most likely to select as the first most important thing in their lives relationships with family or relatives, followed by their own health, the health of another (close) person, and finances/standard of living/housing. When priority ranked areas $1-5$ were combined, the most frequently mentioned area of life was finances/standard of living/housing, followed by relationships with family and relatives, own health, the health of close others, and social life/leisure activities. The most common, freely mentioned first most important effects of longstanding illness on respondents lives were different to those mentioned generically. In relation to longstanding illness they were (in order of frequency), ability to get out and about/stand/walk/go out shopping, being able to work/find a job and effects on social life/leisure activities (office coding from verbatim responses recorded on the questionnaire). When priority ranks $1-5$ are combined, the most frequently mentioned area of life affected was also ability to get out and about/stand/walk/go out shopping, but followed, in a different order, by social life/leisure activities, and availability of work/ability to work.

This research also supports the current trend of developing disease specific health related quality of life questionnaires rather than using generic scales. For example, taking just the first most important area of life affected by the condition, respondents reporting mental health problems and diseases of the nervous system as their longstanding condition were most likely to prioritise the availability of work/ability to work as the first most important area of life affected; respondents with eye problems, with cardiovascular, respiratory and musculoskeletal disorders, were most likely to report the ability to get out and about as the first most important area of life affected; and respondents with endocrine and with digestive disorders were most likely to report dietary restrictions as the first most important area of life affected.

Previous analysis of the domains included in the most popularly used health status scales, which are used to measure health related quality of life, showed several items ranked as important by the public (generically) to be missing. ${ }^{25}$ Health related quality of life questionnaires also need to be sensitive to the type of respondents (for example, in relation to age and sex) and to their condition. O'Boyle et al, ${ }^{15}$ using SEIQoL, reported variation in the weights different groups of respondents attached to the domains of importance mentioned, and also variations with different treatment and recovery periods. This research, together with the results reported here, support the need for hermeneutic approaches to measurement. The development of SEIQoL ${ }^{1213}$ and Guyatt et al's respondent based, disease specific, questionnaire ${ }^{16-18}$ show that this approach can provide useable and valuable data.

Few disease specific or generic instruments have been based on a model of quality of life, few scale developers have attempted to define this concept, and few have been adequately patient based in their development. However, the public, and specific groups of patients, are the best judges of how medical conditions adversely affect the quality of their lives. This paper provides an empirical contribution to the methodological issue of whether to use disease specific or generic quality of life scales, and, given that different domains of life are clearly affected by different types of conditions, the results of this research strongly supports the development and use of the former. It is the first empirical survey to demonstrate the inherent weakness of generic quality of life instruments in contrast to those which are disease specific or idiographic.

I thank Professor C A O'Boyle for helpful advice and willingnes to share information, the staff of OPCS for carrying out the survey and producing the results, Jack Eldridge and Jean Martin for advice on questionnaire design, particularly Jack Eldridg and Angie Osborne for the information on sampling and conducting the analyses, Morag Farquhar for helpful comments, and Lesley Marriott for typing the tables. Those who carried out the original analysis and collection of the data hold no responsibility for the further analysis and interpretation of them. responsibility for the further analysis and interpretation of them. Material from the OPCS omnibus survey, made available through the OPCS, has been used with the permission of the Controller of HM Stationery Office. The dataset is held on the ESRC Data Archive at the University of Essex. The research was funded by the Economic and Social Research Council, and
the author is grateful for their support.

1 Chambers LW, MacDonald LA, Tugwell P, et al. The McMaster health index questionnaire as a measure of quality of life for patients with rheumatoid disease. Rheumat 1982;9:780-4.

2 Bergner M, Bobbitt RA, Kressel S, et al. The sickness impact profile: conceptual formulation and methodology for the profile: conceptual formulation and methodology for the development of a health status measure.

3 Hunt SM, McEwan J, McKenna SP. Measuring health status. Lond,

Ware JE, Snow KK Kosinski M, Gandek B. SF-36 health survey. Manual and interpretation guide. Boston: The Health survey. Manual and interpretation guide. Boston: The

5 Bowling A. Measuring disease. A review of disease specific quality of life measurement scales. Milton Keynes: Open quality of life measurem

6 Ziller RC. Self-other orientation and quality of life. Social Indicators Research 1974;1:301-27. 
7 Rosenberg, R. Quality of life, ethics, and philosophy of science. Nordic fournal of Psychiatry 1992;46:75-77.

8 Andrews, FM. Social indicators of perceived life quality. Social Indicators Research 1974;1:279-99.

9 Neugarten BL, Havighurst RJ, Tobin SS. The measurement of life satisfaction. $\mathcal{F}$ Gerontol 1961;16:134-43.

10 Schneider, $M$. The "quality of life" and social indicators research. Public Administration Review 1976;36:297-305.

11 Zautra A, Goodhart, D. Quality of life indicators: a review Zautra A, Goodhart, D. Quality of life indicators: a review
of the literature. Community Mental Health Review 1979;

12 O'Boyle CA, McGee H, Hickey A, O'Malley K, Joyce $\mathrm{CRB}$. Individual quality of life in patients undergoing hip replacement. Lancet 1992;339:1088-91.

13 O'Boyle CA, McGee H, Hickey A, et al. Reliability and validity of judgement analysis as a method for assessing quality of life. Br F Clin Pharmacol 1989;27:155P.

14 Brehmer B, Joyce CRB eds. Human judgement analysis: the social judgement theory view. Amsterdam: North-Holland, 1988.

15 O'Boyle CA, McGee H, Hickey A, et al. The schedule for the evaluation of individual quality of life (SEIQOL). Administration Manual (draft). Dublin: Department of Psychology, Royal College of Surgeons in Ireland, 1993.

16 Guyatt GH, Berman, LB, Townsend M, et al. A measure of quality of life for clinical trials in chronic lung disease. Thorax 1987;42:773-8.

17 Guyatt GH, Mitchell A, Irvine EJ, et al. A new measure of health status for clinical trials in inflammatory bowel disease. Gastroenterology 1989;96:804-10.

18 Guyatt GH, Nogradi S, Halcrow S, et al. Development and testing of a new measure of health status for clinical trials in heart failure. $\mathcal{f}$ Gen Inter Med 1989;4:101-7.

19 Eldridge J. Technical report. In: OPCS ommibus. Module 83. Quality of life. Initial tables. London: OPCS, 1994.

20 Elliot $\mathrm{D}$. The use of an effective sample size as an aid in designing weighted samples. Survey Methodology Bulletin. London: Office of Population Censuses and Surveys, January, 1990.

21 Bridgwood A, Savage D. General household survey, 1991. London: HMSO, 1993.

22 Thomas M, Goddard E, Hickman M, Hunter P. General Household Survey, 1992. London: HMSO, 1994

23 White A, Nicolaas G, Foster F, et al. Health survey for England, 1991. London: HMSO, 1993.

24 Breeze E, Maidment A, Bennett N, Flatley J, Carey S. Health survey for England, 1992. London: HMSO, 1994.

25 Bowling, A. What things are important in people's lives? A survey of the public's judgements to inform scales of health
related quality of life. Soc Sci Med 1995;41:1477-62. 